\title{
Thoughts and Countermeasures in Teaching Quality Monitoring System in Universities After the Post- epidemic Period
}

\author{
Jingyuan $\mathrm{Xie}^{1, *}$ \\ ${ }^{1}$ College of Humanities, Tianjin Agricultural University, Tianjin, China \\ *Corresponding author. Email: xiejingyuan1700@tjau.edu.cn
}

\begin{abstract}
Great changes have taken place in the teaching mode of colleges and universities before and after the COVID-19 epidemic, resulting in corresponding adjustments and changes in the direction of teaching supervision in colleges and universities. Online and offline mixed teaching will become a new format of college teaching in the postepidemic period. The rapid popularization and popularization of offline teaching and online and offline mixed teaching mode bring new challenges and opportunities for college teaching supervision. In the traditional teaching mode in the past, teaching supervision played an important role in the supervision, inspection, guidance and evaluation of teaching activities, teaching links and teaching principles. Teaching supervision in postepidemic period is an important part of teaching quality monitoring system in colleges and universities. How to participate in it, find its own position, and how to improve its ability and give full play to its role need continuous discussion and deep thinking.
\end{abstract}

Keywords: Teaching supervision, Online and offline, Data quality monitoring introduction.

\section{INTRODUCTION}

The sudden outbreak of COVID-19 caused us to press the pause button in part of the work and life, but the fast forward button was pressed in online teaching. Orderly teaching plans are disrupted, and great changes have taken place in both teaching methods and learning methods. In order to carry out the instructions of "teaching without stopping classes" and "ensuring teaching progress, teaching quality and teaching tasks" put forward by the Ministry of Education, the severity and long duration of the COVID-19 epidemic have changed online teaching from an auxiliary teaching method to a dominant teaching mode. In fact, online teaching is nothing new. In recent years, words such as blended teaching, flipped classroom, massive open online course, micro-class, etc. are familiar to everyone. Teachers are also actively involved in the application and research of various related topics. Some technology companies are also developing related learning platforms, but they have not become the main theme of the teaching work in normal teaching activities. However, the emergence of the epidemic quickly changed this state, and online teaching was launched and promoted in an all-round way under the passive situation. As an important part of teaching supervision in the teaching quality monitoring system, its main task is to serve teaching and teaching management for the purpose, to promote the improvement of teaching quality as the goal, and to collect teaching information as a means [1], to comprehensively supervise, guide, inspect and evaluate the whole teaching practice for both teaching and learning and the whole teaching process, and to put forward teaching suggestions [2].

\section{COLLEGE TEACHING AND SUPERVISION WORK BEFORE AND AFTER THE OUTBREAK}

\subsection{Teaching Situation Before and After the Epidemic}

Both in China and foreign countries, offline classroom teaching has always been the most 
important form of teaching, and it has also become a useful supplement to classroom teaching in longterm education and teaching, which cannot be ignored or denied. With the deepening of education and teaching reform, the influence of modern educational ideas and the enrichment of new educational technology, online teaching has been carried out smoothly and achieved good results. During the epidemic, the Ministry of Education issued the instruction of "Don't stop teaching and stop learning after class suspension", and all universities in China acted quickly. Teachers changed the traditional offline teaching mode in order to start school as scheduled, and all courses were launched online. Various technology companies also launched various teaching service platforms to provide powerful technical support and guarantee for online teaching. According to the online survey, a new teaching and learning model has taken shape after the epidemic, that is, the online and offline hybrid teaching and learning model will become the main teaching and learning model in the future.

\subsection{Teaching Supervision Before Epidemic Situation}

The primary task of teaching supervision is to carry out teaching supervision. According to the annual teaching work arrangement of the teaching management department, the supervision focuses on the inspection of lectures, teaching materials and practice links [3]. In the process of listening to lectures, we should communicate with teachers, conduct discussion and research with students, give feedback on problems in teaching, and urge teachers to improve teaching quality; In addition, the teaching materials checked include whether the teacher's teaching plans and courseware conform to the talent training plan, and the papers are selected to judge whether the coverage rate of knowledge points, subjective and objective ratio, grade discrimination, test validity, etc. meet the standards, and whether the scores are in compliance, etc.; Also check the practical teaching links, including graduation design, plan, work progress, feedback from internship units and completion of practical work, etc.

The second task of teaching supervision is to guide the teaching work. Teaching supervision should go deep into the front line of teaching to fully understand teachers' teaching situation, teaching operation and students' learning effect. Provide guidance to teachers and help students in curriculum design, teaching problems and students' learning difficulties, and provide opinions and suggestions to school management departments to promote the improvement of teaching style and study style, and improve the overall teaching quality and core competitiveness of schools.

The third task of teaching supervision is teaching evaluation. Evaluation feedback mechanism is an important part of teaching quality monitoring system. Professionalism, independence and objectivity of teaching supervision are the key points in teaching monitoring, which can effectively help teaching administrative departments make correct decisions and implement corrective measures more accurately and efficiently. It has played a great role in the long-term teaching supervision under the teaching management line, but its work content, methods and functions are also facing new challenges and tasks with the change of teaching mode in the post-epidemic period.

\section{PROBLEMS IN THE SUPERVISION WORK OF COLLEGES AND UNIVERSITIES IN THE POST-EPIDEMIC PERIOD}

\subsection{Problems in the Supervision Work of Colleges and Universities in the Post- epidemic Period}

Supervisors in colleges and universities are mostly teaching experts or teaching management experts from different majors and disciplines. They are authoritative, experienced, skilled and responsible in their respective professional fields, including some fair and responsible retirees. It is such a supervision team, who may be more likely to stick to the traditional educational philosophy, have little understanding of the mixed teaching methods in online teaching colleges and universities, and can not skillfully apply new educational technology means, so it is easy to cause lack of educational guidance, one-sided educational evaluation and unsatisfactory supervision effect. This requires them to constantly update modern educational concepts, strengthen the study and research of new ideas and theories, master new teaching methods as soon as possible, and establish a full-time, professional and expert supervision team under the new situation. 


\subsection{More Relevant Information and Applying Online Teaching Platform}

With the rapid development of Internet technology, online education has become a new industry in China's network technology. Since the development of online education in China, the Ministry of Education has approved many colleges and universities to become pilot colleges of online education, offering online education courses and issuing online education certificates [4]. However, such online education courses are mostly aimed at self-learners in society. During and after the epidemic, online and offline courses will become a new teaching mode in colleges and universities, which will formally and permanently become an important teaching mode in colleges and universities. With the rapid advancement during the epidemic, many teaching platforms show different chaotic characteristics. Due to the short time and rush to launch, some commonly used platforms have some copper leakage in terms of structure, deficiencies in the evaluation of arts and science projects, insufficient provision of resources and content, and need to be improved in terms of operating experience. Due to the existence of commercial interests, the major platforms also lack effective cooperation and lack of docking with universities of different types and directions, which also causes some problems such as waste of resources, time consumption, different standards, inaccurate evaluation and so on.

\subsection{To Refine and Improve the Online Teaching Evaluation Standards}

From the development of online open courses in China, the earliest online courses only built "static" resources such as network courseware library, case library and test question bank, and did not attach importance to related learning activities and support services [5]. With the rapid development of educational informationization and the change of educational concepts, diversified curriculum models such as recording and broadcasting courses, audio courses, video courses and online and offline mixed courses have emerged. During the epidemic, online courses started in all directions, and showed a "dynamic" trend. However, the proportion of various courses, evaluation methods and means, the combination of online and offline courses, students' examination and evaluation, teachers' teaching effect evaluation, etc. have not kept up with the great changes in the course form, and the evaluation standards are obviously lagging behind. The so- called "there is no standard corresponding inspection, but there is standard corresponding supervision". For the supervision work under the new situation, the research and formulation of standards is the urgent task at present.

From the development of online open courses in China, the earliest online courses only built "static" resources such as network courseware library, case library and test question bank, and did not attach importance to related learning activities and support services [5]. With the rapid development of educational informationization and the change of educational concepts, diversified curriculum models such as recording and broadcasting courses, audio courses, video courses and online and offline mixed courses have emerged. During the epidemic, online courses started in all directions, and showed a "dynamic" trend. However, the proportion of various courses, evaluation methods and means, the combination of online and offline courses, students' examination and evaluation, teachers' teaching effect evaluation, etc. have not kept up with the great changes in the course form, and the evaluation standards are obviously lagging behind. The socalled "there is no standard corresponding inspection, but there is standard corresponding supervision". For the supervision work under the new situation, the research and formulation of standards is the urgent task at present.

\section{COUNTERMEASURES FOR THE IMPLEMENTATION OF SUPERVISION WORK IN COLLEGES AND UNIVERSITIES IN THE POST-EPIDEMIC PERIOD}

The gradual formation of the new teaching mode also requires the further improvement of the teaching quality monitoring system in colleges and universities, as well as the rapid change and followup of the supervision work methods and ideas. Educational ideas, working methods, evaluation mechanisms, etc. should be adjusted in working practice to keep up with the changing teaching methods.

\subsection{To Give Full Play to the Supervisory and Guiding Role of Teaching Supervision}

In the online and offline mixed teaching mode, the biggest uncertainty is online teaching. Traditional classroom teaching has been used for many years, and the evaluation system is perfect 
and mature. Only online teaching and mixed teaching have brought many new problems, which bring new challenges to the teaching supervision in colleges and universities. As a teaching supervisor, we should adhere to the consistent working principles. First of all, the teaching quality cannot be changed. From the perspective of teaching quality assurance, no matter how the online teaching status, content and methods change, the fundamental purpose of teaching supervision in colleges and universities cannot be changed, that is, the course quality, classroom quality and students' learning and development quality cannot be ignored or reduced; Secondly, the nature of supervision cannot be changed. Supervision should take supervision, diagnosis, early warning and guidance as its duty. These functions should not be weakened, but should be strengthened. Because only when supervision is in place can problems be found and solved. Third, the professional nature of supervision can't be changed. Supervision is different from administration and teaching and scientific research. It should follow certain rules in teaching content, teaching methods and effect evaluation. Only specialization can embody scientificity, realize standardization and improve authority, and achieve the goal of improving teaching quality and teaching level.

After the epidemic, the teaching methods of colleges and universities have been passively changed, and the online and offline teaching mode has basically taken shape, while the online course platform is operated by many private enterprises and social groups, and many monitoring rules and regulations have yet to be established. Compared with the past, the work of college supervisors will face a wider scope, more objects and a wider form, so supervisors will face more severe challenges. First of all, while supervising the traditional classroom, we should strengthen the supervision of online teaching, formulate online teaching implementation plans according to school conditions and academic conditions, formulate relevant management measures, and strengthen the supervision of teaching platforms; Secondly, it guides teachers to select the best resources, formulate online teaching solutions, make full use of the characteristics and advantages of online teaching, and promote the deep integration of information technology and education and teaching to promote the change of teachers' teaching methods and students' learning methods; The third is to establish a linkage guarantee mechanism for curriculum quality assurance, make full use of the analysis data of students' learning behavior, understand students' online learning in a timely and comprehensive manner, combine online learning classroom learning, strengthen multiple evaluation of online learning, and promote the perfect combination of online and offline teaching and learning.

\subsection{To Refine and Improve the Teaching Supervision Standards}

As the saying goes: If there is no standard, it is called inspection; if there is a standard, it is called supervision. The epidemic situation is an emergency. During this period, two standards should be emphasized in undergraduate teaching, one is the bottom line standard, and the other is the basic standard. The so-called bottom line standard is to ensure "stop teaching and stop learning" according to the requirements of the Ministry of Education. Its core index is to require all courses of online teaching in all disciplines and majors to be opened, the teaching progress to be guaranteed, and the teaching resources to be compliant. The basic standard is to ensure that all kinds of online teaching quality are basically qualified. After the epidemic, the teaching form has changed, and the new teaching mode has gradually formed. The standard of supervision has also been adjusted for the development of online courses and the implementation of mixed teaching. Several indicators should be considered: First, the operation of the selected teaching platform is high-quality and the use is reasonable; Second, whether the content and form of teachers' teaching are innovative and scientific and reasonable; third, pay attention to students' learning performance and learning effect, evaluate students' learning situation more scientifically and reasonably, encourage students' interest in learning and improve teaching quality. Pay attention to the quality of online teaching from the following aspects: First, use new bowls to hold old meals. After the epidemic, although the teachers' online courses will continue to adopt the forms of recording and broadcasting, micro-classes, etc., the content of the lectures is still full of people, and it will make students feel boring if they are not used; Second, teaching resources are supplied through multiple channels, and the quality is uneven, so teachers should give students timely guidance. Make it difficult for students to choose; Third, the online teaching interaction is insufficient, and some teachers are still full of people. They only move the offline courses to the online line without highlighting the advantages of online courses and 
affecting the teaching effect; Fourthly, according to the different types of courses, arrange the proportion of online and offline courses so as to complement each other and bring out the best in each other.

\subsection{To Standardize the Evaluation Points and Indicators of Online Teaching and Online and Offline Mixed Teaching}

After the sudden epidemic, the online course construction in colleges and universities has been groping in difficulties, bravely practicing, constantly summing up experience and learning lessons. The supervision work in colleges and universities is also adjusting the evaluation standards of online course construction. On the basis of accumulating experience and finding problems, the supervision teams in colleges and universities have also worked out online course evaluation systems suitable for their own characteristics. Now the evaluation standards of online courses and mixed teaching in various colleges and universities have also been released. Whether online or offline, the fundamental nature of education remains unchanged, but the ways and means of disseminating knowledge have changed, and everything has changed. Based on the evaluation standards of online teaching and mixed teaching in some universities, the main evaluation points are as follows:

First of all, it is necessary to evaluate whether the electronic teaching plan and audio and video resources of the teaching resources and content are in line with the teaching, whether the online teaching has clear goals and clear ideas, reasonable teaching time arrangement, and appropriate interaction between offline and offline; Whether the teaching content can accurately grasp the key points and difficulties of the course, whether the online resources can be effectively used, the teaching process is reasonably organized, the audio and video recording and utilization are appropriate, and the methods and means are properly and effectively used.

Secondly, it mainly evaluates the classroom teaching of online courses, including teaching design and methods, which can meet the syllabus and classroom teaching objectives, and can be taught according to the requirements of professional certification. The teaching content is enriched and the online teaching requirements are clear; Online teaching resources can better reflect or contact the new ideas, new concepts and new achievements of discipline development, and serve the graduation requirements of curriculum objectives; The focus of online teaching process is outstanding, the regulations are clear, the content is inherited from the past and the future, and it is gradual and can reflect the interactivity of online teaching; In the online teaching process, online course assignments can be arranged in a variety of ways, and timely feedback can be given to students' questions.

Third, we should evaluate the rationality of the teaching organization process. The teaching process can reflect the characteristics of online courses, and the video and audio materials are decent and inspiring, which can effectively mobilize students' thinking and learning enthusiasm; The lecturers can skillfully and effectively use modern teaching methods such as multimedia, and the classroom resources can refer to the online resources of other universities in China. The homework design is closely related to the teaching content, and the structure is reasonable. The teaching interaction is coordinated with multimedia, and students' questions can be answered in real time.

Fourth, we must evaluate the teaching team and teaching characteristics, including the matching degree between classroom resources and team division of labor, the smooth, accurate and vivid use of audio and video, the appropriate pace of speech, the reasonable and appropriate division of labor of teaching team, and the natural and generous teaching style; According to the teaching characteristics of online courses, we can start from three aspects: teaching philosophy, teaching methods and teaching process, so as to be practical, clear in thinking, clear in viewpoint and fluent in expression, and effectively reflect the advantages of online and offline teaching resources. Self-designed or quoted electronic resources can better assist students to achieve the teaching objectives in class. Finally, we should evaluate the effect and students' learning effect, mainly from the aspects of advanced teaching concept, outstanding style, strong appeal and teaching effect, as well as from the aspects of students' participation, teaching interaction and overall effect, etc.

\section{CONCLUSION}

Teaching quality monitoring refers to the internal analysis and evaluation of factors such as teaching objectives, teaching organization, teaching activities, teaching style and teaching effect, etc. according to the law of education, and effectively 
regulates the teaching work through the feedback of teaching information to promote the continuous improvement of teaching quality. Teaching supervision is an important component of the teaching quality monitoring system, and its work makes the objectives of the quality monitoring system clearer, the supervision system more perfect and the feedback mechanism more perfect [6]. College teaching supervisors have a lot of knowledge to learn, so they can improve their awareness, ideas and skills to play a bigger and more active role in the future teaching supervision and guidance work and make greater contributions to the improvement of teaching quality.

\section{AUTHORS' CONTRIBUTIONS}

This paper is independently completed by Jingyuan Xie.

\section{REFERENCES}

[1] Chen Yan. Reform of curriculum assessment methods in private colleges and universities [J]. Western quality education, 2020,02:25.

[2] Deng Ling, Xiao Huazhu. On the role of teaching supervision in university teaching quality monitoring system [J]. Contemporary Education Forum (second half), 2009,01:18921.

[3] Wei Anbang. Teaching supervision function "guidance, training, research and reference" four in one $[\mathrm{J}]$. Chemical Vocational and Technical Education, 2007,02: 20.

[4] Wu Guangzhi. Transformation and reflection from distance education to online education [J]. Continuing Education Research, 2017, (1): 79-80.

[5] Yang Xiaohong, Zhou Xiaozhang, Li Yunfu. Research on the teaching quality identification of online open courses in colleges and universities from the perspective of value subject needs $[\mathrm{J}]$. China Audio-visual Education, 2018, (7): 45-51.

[6] Xue Wen, Yang Ningning, Zhang Huizhi and Zhang Wenying. Research on the Role and Problems of Teaching Supervision in Teaching Quality Monitoring System in Colleges and Universities [J]. Teaching Research, 2016,04,4-10. 